\title{
The link between chronic pain and Alzheimer's disease
}

\author{
Song Cao ${ }^{1,2,3}$, Daniel W. Fisher ${ }^{3}$, Tain Yu ${ }^{2}$ and Hongxin Dong ${ }^{3^{*}}$
}

\begin{abstract}
Chronic pain often occurs in the elderly, particularly in the patients with neurodegenerative disorders such as Alzheimer's disease (AD). Although studies indicate that chronic pain correlates with cognitive decline, it is unclear whether chronic pain accelerates AD pathogenesis. In this review, we provide evidence that supports a link between chronic pain and AD and discuss potential mechanisms underlying this connection based on currently available literature from human and animal studies. Specifically, we describe two intertwined processes, locus coeruleus noradrenergic system dysfunction and neuroinflammation resulting from microglial pro-inflammatory activation in brain areas mediating the affective component of pain and cognition that have been found to influence both chronic pain and AD. These represent a pathological overlap that likely leads chronic pain to accelerate AD pathogenesis. Further, we discuss potential therapeutic interventions targeting noradrenergic dysfunction and microglial activation that may improve patient outcomes for those with chronic pain and AD.
\end{abstract}

Keywords: Chronic pain, Alzheimer's disease, Locus coeruleus, Norepinephrine, Noradrenergic system, Microglia, Prefrontal cortex

\section{Introduction}

Chronic pain, defined as pain lasting more than 3 months, is very common in the elderly and is a significant issue in both individual clinical practices and the healthcare system. The prevalence of chronic pain in older people living in the community is reported to be $38.5 \%$ [1], which is higher than that in the adult population at large (19\%) [2] and schoolchildren (6\%) [3]. Though chronic pain is often understood as aberrations in sensory processes, it is also highly associated with cognitive, emotional, and social dysfunction [4]. In contrast to acute pain, cognitive and emotional deficits seem to be particularly prominent when pain turns chronic, and the many failed treatments that solely target peripheral mechanisms of pain underly the increased complexity of pain perception with chronicity $[5,6]$. Dysfunctions in pain perception mediated by the central nervous system (CNS) are likely to play a key role in the process of pain chronification, and central sensitization in pain processing pathways influences cognitive and emotional processing, which has been supported by both

\footnotetext{
* Correspondence: h-dong@northwestern.edu

${ }^{3}$ Department of Psychiatry and Behavioral Sciences, Northwestern University Feinberg School of Medicine, 303 East Chicago Avenue, Chicago, IL 60611, USA

Full list of author information is available at the end of the article
}

human $[7,8]$ and animal work $[9,10]$. Together, a bidirectional interaction likely exists between chronic pain and cognitive deficits.

Alzheimer's disease (AD), a neurodegenerative disorder and most common form of dementia, characterized by cognitive and behavioral impairments, is often co-morbid with chronic pain. The reported prevalence of chronic pain in AD patients was $45.8 \%$, based on a recent meta-analysis [11]. In fact, pain may be underestimated in $\mathrm{AD}$ patients as they may be unable to communicate their pain and request attention as effectively as their cognitively normal peers [12]. Importantly, pain is observed more prevalently in patients with severe dementia [13], and intensity of pain is also positively correlated with dementia severity [14-16]. Though a bidirectional correlation exists between chronic pain and $\mathrm{AD}$, a clear mechanistic link remains elusive. Growing evidence suggests patients with chronic pain or $A D$ share some common pathologies, including abnormalities of the noradrenergic system in the locus coeruleus (LC) [17], activation of microglia in brain areas such as the frontal cortex, and increased central neuroinflammation in these regions [18]. The LC extends axons that innervates most brain area and is the main center of

(C) The Author(s). 2019 Open Access This article is distributed under the terms of the Creative Commons Attribution 4.0 International License (http://creativecommons.org/licenses/by/4.0/), which permits unrestricted use, distribution, and 
norepinephrine (NE) synthesis and subsequent neurotransmission in the CNS. Interestingly, it has been suggested that changes in LC-NE signaling contributes to microglial dysfunction [19].

In this review, we provide current evidence for the link between chronic pain and $\mathrm{AD}$ and the overlapping pathological changes in these two disorders. Additionally, we discuss the possibility that chronic pain aggravates $\mathrm{AD}$ pathogenesis through dysfunction of LC-NE signaling and subsequent microglial activation-induced neuroinflammation.

\section{The link between chronic pain, cognitive impairment, and dementia}

It has been reported that chronic pain is associated with increased self-rated and objective cognitive deficits $[15,20]$. These cognitive deficits are not specific to a particular pain modality and can be observed in fibromyalgia [21], postherpetic neuralgia [22], and chronic back pain [23], to name a few. Epidemiological analyses of community-dwelling residents and pain clinics estimate that at least $50 \%$ of people living with pain report cognitive problems [24], and a similar proportion demonstrate impairment on objective cognitive tests [25]. Further, clinical observations indicate that the intensity of pain is positively correlated with the degree of cognitive impairment [10,26, 27].

Chronic pain is also associated with dementia. In the Einstein Aging Study, one of the longest running prospective cohort studies of aging, 1114 elderly participants [28] were assessed and 114 (10\%) of the subjects developed dementia over 4.4 years [29]. In this study, higher levels of pain interference, defined as the degree of pain-related impairment in activities of daily living, were associated with a higher probability of developing dementia [29]. However, it is reported that there was no relationship between the intensity of pain and developing dementia [29], which may be due to (1) dementia patients and their caregivers routinely underreport pain intensity, (2) chronic pain may manifest differently in dementia patients, and (3) more severe cognitive impairments leading to reduced ability to articulate pain concerns [30-32]. Another study [33] also supported pain interference being significantly and positively associated with $\mathrm{AD}$ and related dementia (ADRD). In this cohort of 25,009 older adults ( $>65$ years), those with pain interference either with or without osteoarthritis had significantly higher odds of ADRD relative to those without osteoarthritis or pain interference [33]. Overall, these studies suggest that chronic pain, especially in patients with pain interference, may hasten dementia pathogenesis in addition to its effects on subclinical cognitive dysfunction.

Another similarity is that chronic pain and AD display abnormalities of gray matter volume, and neuroimaging suggests that cognitive decline in patients with chronic pain may be related to gray matter volume changes in the brain [4]. Many of these altered brain areas are involved in sensory perception, the affective component of pain, and cognition [34, 35]. For instance, gray matter volume loss has been found in the amygdala, entorhinal cortex, parahippocamal gyrus, anterior cingulate cortex, thalamus, and insula [36-38]. Additionally, reduced gray matter volume in brain areas involved in cognitive function, such as the dorsolateral prefrontal cortex (dlPFC) [39], medial prefrontal cortex (mPFC) [37], and hippocampus [40]. We found that postherpetic neuralgia patients displayed decreased gray matter volume in the frontal lobe compared with healthy controls or otherwise healthy herpes zoster patients [41]. Interestingly, some of these areas are among earliest sites of degeneration in $\mathrm{AD}$ [42], and cortical gray matter volume is correlated with cognitive decline in $\mathrm{AD}$ [43]. Though different pathological mechanisms may exist and independently contribute to gray matter atrophy in chronic pain and $\mathrm{AD}$, an interaction may be present in these two disease states that synergistically increases neurodegeneration and cognitive decline.

To date, a considerable number of animal experiments have investigated the cellular and molecular mechanisms between chronic pain and cognitive deficits [44, 45]; however, few studies have focused on whether a common mechanism underlies cognitive decline in comorbid chronic pain and AD. In one notable study [45], chronic inflammatory pain accelerated cognitive impairment in 5-month old APP/PS1 mice, a prominent $\mathrm{AD}$ model, but not in wildtype animals. As APP/PS1 mice rarely develop overt cognitive deficits before 9-12 months of age, the development of memory impairment in this study suggests that chronic pain accelerates AD pathogenesis and subsequent cognitive decline. While this study suggests animal models may be useful for investigating a mechanistic relationship between $A D$ and chronic pain, this investigation still needs to be done.

\section{Chronic pain induces dysfunction of the LC-NE system and pro-inflammatory microglial activation}

The LC has been implicated in a variety of physiological functions including attention, memory, emotion, stress reactions, and pain modulation [46]. The LC is located in the dorsal pontine nucleus and provides descending noradrenergic input to the spinal cord, forming the LCspinal descending pain modulation system. It also extensively projects to most regions of the brain, particularly the frontal cortices and the limbic system [47], and is well known as the predominant source of the neurotransmitter NE in the brain [48]. 


\section{Chronic pain induces dysfunction of LC-NE system}

Dysfunction of LC-NE system associated with chronic pain has been reported mostly in animals. Significant increases in the expression of tyrosine hydroxylase, dopamine beta-hydroxylase $(\mathrm{D} \beta \mathrm{H})$, the NE transporter, the $\alpha_{2}$-adrenoceptor, and burst firing have been seen in the LC of rats with a chronic constriction injury, a widely used neuropathic pain model $[47,49]$. This results in more NE release [50,51], although these changes were only evident when pain became chronic (28-day pain duration) and not during the acute period (7-day pain duration) $[47,49]$. Although most of the animal studies reported that the LC is activated in chronic pain, one study showed opposite results [52]. In particular, in streptozocin-treated rats, a model of diabetic neuropathy, LC firing activity and expression levels of tyrosine hydroxylase, pCREB, and the NE transporter were reduced in the $\mathrm{LC}$ when anxiety-like and depression-like behaviors were observed, a time point considered to be representative of chronic pain [52]. The distinct nociceptive sensitivity time-courses as well as the LC functions between the chronic constriction injury and streptozocin models indicate that specific neuroplastic mechanisms depend on pain modality [52], which adds a layer of complexity in determining how chronic pain may be affected by LC-NE neurotransmission.

Changes in LC function and plasticity will affect NE transmission in numerous brain regions, and it is very possible that changes in LC-NE function are not uniform but instead vary based on downstream targets. For example, abnormally increased LC-PFC neurotransmission has been widely reported in animals with chronic pain and leads to increased noradrenergic fiber sprouting and intrinsic excitability in the PFC, mediated in part by $\alpha_{2}$-adrenoreceptors and HCN channels [53]. This increase in plasticity in the PFC coincides with shifting NE neurotransmission in other specific brain areas innervated by the LC [54]. Despite this increase in noradrenergic markers, microdialysis techniques showed that 28 days after chronic constriction injury, no significant difference was found in basal NE release in the LC and PFC in rats [49]. However, another study showed that in the PFC, the sensitivity of $\alpha_{2}$-adrenoceptors is enhanced, and 6 weeks after spinal nerve ligation, the NE content of the PFC was augmented significantly, coupled with impaired attention [50]. These data suggest that pain duration is an important factor for the neuroplastic LC changes and also suggest that changes in LC-NE neurotransmission is likely more nuanced than those determined by measuring basal neurotransmission alone [47].

Overall, chronic pain-induced LC-NE system dysfunction during chronic pain is complex and likely depends on the chronic pain duration, modality, and downstream neuron function and location. However, in terms of brain regions that are affected by cognition, such as the $\mathrm{PFC}$, enhanced neurotransmission of NE results in increased excitability that coincides with aberrant cognitive and emotional behaviors.

\section{Chronic pain induces microglial activation and neuroinflammation}

Microglia are the primary innate immune cells in the CNS, which is otherwise relatively immunoisolated [55]. As one of the constituent cells of blood-brain barrier, microglia express many kinds of receptors which recognize exogenous or endogenous insults to the CNS and initiate an immune response [56]. For example, it has been reported that microglia control the spread of neurotropic virus infection [57], which can induce encephalitis and neurodegeneration [58].

Microglial activation includes pro-inflammatory activation and anti-inflammatory activation [59, 60]. Microglial pro-inflammatory activation promote neuropsychiatric disease through release of pro-inflammatory molecules such as tumor necrosis factor- $\alpha$ (TNF- $\alpha$ ), interleukin (IL)-1 $1 \beta$, IL6 , inducible nitrous oxide synthase (iNOS), and reactive oxygen species [60]. Activated microglia due to chronic pain may play critical roles in pain occurrence and maintenance [61]. In chronic pain, neuroinflammation driven by microglia is a characteristic feature [62]. In fact, microglia are initiators of a postinjury, neuroimmune response that contributes to the transition from acute to chronic pain [63]. In the chronic pain state, pro-inflammatory microglia release cytokines and chemokines associated with inflammation, such as IL-6, IL- $1 \beta$, and TNF- $\alpha[64,65]$. This proinflammatory state leads to changes in synaptic remodeling, brain connectivity, and network function [66].

Chronic pain-induced microglial activation and neuroinflammation have been reported in both humans and animal models. In one study using PET-MRI, patients with chronic lower back pain showed increased microglia and astrocyte activation in the thalamus and the putative somatosensory representations of the lumbar spine and leg, as evidenced by elevated signal of translocator protein, a marker of microglia and astrocytes [67]. In another study, by using $\left[{ }^{11} \mathrm{C}\right] \mathrm{PBR} 28 \mathrm{PET}$, microglial activation signal was widely elevated in certain cortical regions of patients with fibromyalgia, a condition typified by chronic, neuropathic pain [68].

Additionally, a large number of animal studies have shown that chronic pain increases microglial proinflammatory activation and neuroinflammation in the brain. Specifically, microglial activation has been detected in the PFC [64, 69, 70], hippocampus [71], anterior cingulate cortex [72], amygdala, nucleus accumbens, thalamus, and sensory cortex $[64,73,74]$ in different kinds of chronic pain animal models [75]. For instance, rats with spared nerve injury showed microglial activation in the PFC as evidenced by increased expression of CD68, iNOS, 
IL-1 $\beta$, IL-6, TNF- $\alpha$, and 8-OH-dG [70, 74]. Spared nerve injury mice also displayed TNF- $\alpha$ upregulation in bilateral hippocampi [65]. Similarly, rats with spinal nerve ligation showed microglial activation in the PFC [69], and mice with chronic constriction injury developed increased microglial inflammation in the $\mathrm{mPFC}$, hippocampus, and amygdala evidenced by increased CD11b and TNF- $\alpha$ expression [64].

In all, chronic pain is associated with upregulation of pro-inflammatory microglia in varied brain areas, including those responsible for cognition and emotion. Microglial activation induces neuronal dysfunction, such as the LC-NE dysfunction, which may feed forward to enhance further microglia-driven neuroinflammation.

\section{Chronic pain may aggravate AD neuropathogenesis through LC-NE-induced microglial neuroinflammation}

Chronic pain and AD brains not only display abnormal LC structure and function but also dynamic changes in NE turnover in LC-projecting areas [47, 76]. Although the shifts of NE content may not perfectly overlap in all brain areas in these two disease states, LC-NE pathological changes in select regions could be one of the initiators that leads to a final common outcome: pro-inflammatory activation of microglia and neuronal dysfunction.

\section{Dysfunction of the LC-NE system in AD brain}

Similar to chronic pain, the function and structure of the $\mathrm{LC}$ are disrupted in $\mathrm{AD}$, and the $\mathrm{LC}$ is one of the earliest brain regions affected during $\mathrm{AD}$ development and progression [77]. A loss of LC-noradrenergic neurons is observed in autopsy specimens of AD patients, with estimated 50\% [78] to 60\% [79] LC cell loss, which is more dramatic than the $41 \%$ neuron loss observed in the PFC [80]. However, there is evidence that axonal sprouting and dendritic arborization increases, perhaps as compensation for the loss of cells [81]. Concomitantly, increased activity of surviving $\mathrm{LC}$ neurons in $\mathrm{AD}$ patients is also reported [82, 83], and post-mortem autoradiography detected significantly decreased NE transporter in the human $\mathrm{AD}$ brain, again suggesting compensatory mechanisms adjusted for cell loss [84].

Due to the complexity in these degenerative and compensatory mechanisms, it is not surprising that there are conflicting reports of the levels of $\mathrm{NE}$ in various brain areas in AD patients. Some reported a decrease in NE and some demonstrated that NE levels in $\mathrm{AD}$ patients remain constant or even elevated in the cerebrospinal fluid $[76,78,85]$. These differences in NE neurotransmission across studies may also reflect different points in AD pathogenesis. Therefore, although neuron loss occurs in the LC, NE content does not necessarily decrease in the $\mathrm{AD}$ brain, as the system likely compensates by increasing LC excitability and decreasing NE reuptake, and increased NE early in the disease may further exacerbate neurodegeneration. Although noradrenergic neuron loss in the LC correlates significantly with the duration of $\mathrm{AD}$ [86], NE concentration decreases were found in brain regions associated with cognitive deficits, namely the midtemporal cortex and the orbital-frontal cortex [78]. Mirroring the loss of LC neurons in humans, animal models of AD also demonstrated significant aberrations in the LC-NE system. For instance, the APP/PS1 mouse has demonstrated degenerated noradrenergic neurons and fibers in the LC [87]. Further, hyperphosphorylated tau causes reduced NE neurotransmission from the LC to the forebrain and certain subcortical areas, such as the hippocampus, suggesting that tau may be one of the AD-related mediators of LC dysfunction [88]. These studies suggest that patients with $\mathrm{AD}$ have a progressive decrease in LC neurons, and part of the clinical symptoms of AD may be due to reduced noradrenergic neurotransmission mediated by LC degeneration, especially in mid- and late-stages of disease progression [89].

\section{NE turnover influences microglial activation and neuroinflammation}

Homeostasis of the LC-NE system is important for controlling central inflammation because numerous studies have shown that NE can effectively inhibit inflammation, including microglia-related neuroinflammation [19]. On the other hand, recent studies indicate that NE could be pro-inflammatory [90]. Therefore, when the homeostasis of LC-NE system is destroyed, either excessive or insufficient NE may lead to neuroinflammation.

Microglia are well equipped to respond to NE signaling by expressing the noradrenergic $\alpha_{1 \mathrm{~A}}, \alpha_{2 \mathrm{~A}}, \beta_{1}$, and $\beta_{2}$ receptors [91, 92] and strong interactions exist between $\mathrm{NE}$ and microglia [87, 92]. Some evidence supports that pro-inflammatory activation of microglia may be due to activation of the LC and abnormal and excessive release of NE [90]. NE enhances $A \beta$-mediated IL-1 $\beta$ secretion through action at $\beta$-adrenoceptors in THP-1 cells [93]. $\mathrm{NE}$ also increases COX-2 and prostaglandin E2 production induced by LPS via $\beta$-adrenoreceptors in rat primary microglia [94]. NE plays both roles as a facilitator or a suppressor for microglial pro-inflammatory reactions via activating cAMP and modulating downstream MAPK and NF-KB signaling [95]. Therefore, chronic pain-induced LC-NE neuron hyperactivity and increased supply of NE to brain areas such as PFC may result in microglial pro-inflammatory activation and exacerbate neuroinflammation in these areas in $\mathrm{AD}[64,70]$.

However, more evidence indicates that NE inhibits microglial activation and suppresses the production of pro-inflammatory factors such as IL-6 and TNF- $\alpha$ [91]. 
Studies suggested that NE dampens microglial reactivity [96], as NE negatively regulated the transcription of inflammatory genes encoding pro-inflammatory cytokines and chemokines in microglia [97, 98], likely through direct action on adrenergic receptors on these cells [92]. For instance, noradrenergic depletion with DSP4 treatment increased microglial activation and the expression of iNOS and COX2 in the hippocampus and the frontal cortex of aged APP V717 transgenic mice [87]. Coactivation of $\beta 1$ and $\beta_{2}$ in hippocampal slice cultures reduced microglial activation from a pro-inflammatory LPS plus oxygen-glucose deprivation insult and resulted in an overall reduction in TNF- $\alpha$, IL-6, and MCP-1 [99]. Similarly, $\beta$-adrenergic agonism in microglia co-cultured with cortical neurons protected these cells from death by downregulating TNF- $\alpha$, IL- 6 , and free radical expression $[100,101]$. In line with the dampening of microglial activation, catecholamines also inhibit nitric oxide production from microglia, perhaps by causing a decrease in iNOS [101].

\section{Activated microglia and neuroinflammation promote AD pathogenesis}

\section{Microglial activation and neuroinflammation increase in} $\mathrm{AD}$

Recently, inflammation-associated PET studies demonstrated microglial activation in the brains of AD patients. In addition, microglial activation was found occurring before cognitive decline in $\mathrm{AD}$ patients, suggesting that it may be an early precipitant of AD progression [102]. By using PET-MRI in AD patients, two peaks of microglial activation were detected during the trajectory of $\mathrm{AD}$ pathogenesis, which may represent an early protective peak and a later pro-inflammatory peak [103].

Microglial activation and neuroinflammation are found in the brains of $\mathrm{AD}$ animal models. For example, microglia show increased proliferation in well-characterized mouse models of AD, including APP/PS1, 5XFAD, and APP23 mice [104, 105], and increased expression of proinflammatory markers such as CD36, CD14, CD11c, MHC-II, and iNOS [106, 107].

Microglial activation may play a dual role in AD. At the early stage of $\mathrm{AD}$, activated microglia display mainly antiinflammatory phenotypes [108], while chronic activation of microglia contributes to neurotoxicity and induces synapse loss by triggering pro-inflammatory cascades $[109,110]$. Similar to microglial activation in chronic pain, loss of microglial homeostatic functioning and subsequent transition to prolonged and pathological neuroinflammation exists in $\mathrm{AD}$ patients $[109,110]$. Despite the complexity in the role of microglia in $\mathrm{AD}$ pathogenesis, studies suggest that during $\mathrm{AD}$ progression, microglia predominantly support proinflammatory processes and promote cognitive decline. In fact, reactivations of microglia and neuroinflammation are now considered characteristics of $\mathrm{AD}$ pathogenesis [111].

\section{Microglial activation and neuroinflammation hastens $A D$ pathogenesis via $A \beta$}

Microglia are found clustered around amyloid plaques in both humans [112] and AD mice [113] and have been shown to regulate plaque dynamics [114]. Under nonpathological conditions, microglia play an important role in regulating $A \beta$ deposition [115], and abundant evidence suggests that properly functioning microglia are involved in the clearance of $A \beta$ and limiting the expansion of plaques $[116,117]$. With early exposure to $A \beta$, activated microglia may phagocytose toxic $A \beta$ and produce survival-promoting trophic factors in the AD brain [118]. However, some studies show that microglia become activated with prolonged exposure to $A \beta$ and will undergo a pro-inflammatory response $[114,119]$, resulting in the secretion of synaptotoxic/neurotoxic cytokines, chemokines, and reactive oxygen/nitrogen species [118, 120, 121]. This is highlighted by studies in post-mortem $\mathrm{AD}$ brains and mouse models, where prolonged $\mathrm{A} \beta$ deposition leads to alterations in microglia, such as P2X7 receptor upregulation and activation of the innate immune response characterized by release of pro-inflammatory cytokines, acute phase proteins, and complement components [122-124] that cause microglia-mediated synapse and neuron loss [125].

In addition, microglia may release large amounts of fibrillar $A \beta$ and can promote $A \beta$ plaque formation [126]. In addition to directly mediating neurodegeneration, microglia-derived ASC specks may cross-seed A $\beta$ in AD, causing progression of the proteinopathy and spread of pathogenesis across the brain [127]. Although the relationship between microglia and $A \beta$ is complex, the sustained presentation of $A \beta$ seems to promote proinflammatory activation of microglia that ultimately furthers the synapse loss that is so highly correlated with cognitive decline.

\section{Microglial activation aggravates $A D$ via tau pathology} Neurofibrillary tangles in the brain of AD patients increase in parallel with colocalized expression of microglial pro-inflammatory activation and tau kinases [128]. Hyperphosphorylated tau, misfolded tau, and truncated tau co-occurs with microglia proliferation and increased expression of inflammatory genes such as Aif1 (encoding IBA-1), Ptgs 2 (encodes COX2), $I L-1 \beta, I L-6$, and Tnf- $\alpha$ in the LC [128]. These findings suggest that activated microglia may participate in driving tau pathology in AD.

It has been extensively reported that trans-synaptic propagation of tau occurs through anatomically connected synapses; however, microglia are implicated in spreading tau [129] by endocytic phagocytosis and 
exocytic release of exosomes in pathways independent of synaptic transmission [130]. Microglial uptake and exosomal release of tau may play a key role for tau spreading between cells in the brain [130]. In vitro, microglia isolated from human $\mathrm{AD}$ cases and rTg4510 tauopathy mice are capable releasing tau seeds [129]. These microglia took up tau in the conditioned media but cannot entirely neutralize its seeding activity. These data suggest that microglia only have limited capacity to take up and break down seed competent tau, and inefficiency in this process may play a role in the spread of tau pathology [129]. In addition, evidence indicates that reactive microglia are sufficient to drive tau pathology and are highly correlated with the spread of pathological tau in the brain [131], while depletion of microglia suppresses tau propagation [130]. In transgenic tau mouse models, when microglia were activated by deleting CX3CR1, tau pathology was increased [131, 132]. These studies suggest that microglial activation contributes to tau pathology during $\mathrm{AD}$ pathogenesis.

\section{Therapeutic implications of targeting the LC-NE system and microglia in co-morbid chronic pain and AD}

\section{Increasing NE}

Maintaining the balance of the LC-NE system may help the prevention and treatment of AD. Animal studies suggested that modulation of microglial activation by increasing $\mathrm{NE}$ level would be one approach for $\mathrm{AD}$ alleviation [133]. NE could be neuroprotective against $A \beta$ toxicity through redox cycling and reduction of intracellular oxidative stress [134]. The NE precursor L-threo-3,4-dihydroxyphenylserine (L-DOPS) rescued spatial memory deficits in $\mathrm{DBH}^{-1-} \mathrm{AD}$ mice [135]. It is also reported that L-DOPS restored the balance of inflammation, facilitated microglia migration and $A \beta$ phagocytosis, and reversed learning deficits in DSP4-induced LC lesion AD mice [87]. Thus, increasing NE concentrations may facilitate antiinflammatory functions of microglia in $\mathrm{AD}$ and promote microglial migration and phagocytosis of $A \beta$.

Although aforementioned animal studies showed that increasing NE levels can improve AD symptoms, the efficacy of this kind of treatment still needs to be tested clinically. In a clinical trial in AD patients, atomoxetine, a selective noradrenergic reuptake blocker, did not improve cognitive function [136]. However, as the relative NE levels and downstream pathological changes are varied based on disease stage and brain location, increased NE may result in microglial activation and inflammation priming if it occurs during certain phases of AD pathogenesis [137], and increased NE is even suspected to be the etiological factor of AD [138]. Addressing this issue will help to judge the feasibility of NE therapy during different stages of AD pathogenesis.
Meanwhile, if AD patients have co-morbid chronic pain, it needs to be realized that LC-NE system dysfunction is likely the result of a combination of the two disease processes. Patients with AD have a decrease in noradrenergic neuron in the LC, although some studies suggest that the remaining noradrenergic neurons can compensate for this cell loss by increasing their activity and may even increase NE neurotransmission in the AD brain during certain stages of the disease $[83,138]$. A dichotomy may emerge between $\mathrm{AD}$ patients with co-morbid chronic pain and those without: in the AD patient without chronic pain, there may be a relative deficiency of $\mathrm{NE}$ in brain regions, especially when compensatory mechanisms have been exhausted, and increasing NE supply in these brain areas may be beneficial; however, in AD patients with chronic pain, NE neurotransmission may be enhanced in brain areas such as the mPFC and hippocampus, which could possibly result in microglial pro-inflammatory activation [70]. Therefore, in AD patients with chronic pain, supplementation of NE via reuptake inhibitors may paradoxically exacerbate $\mathrm{AD}$ pathogenesis.

\section{Inhibiting microglial activation}

Another possible way to prevent and relieve AD is to directly inhibit pathological activation of microglia. Minocycline, a semisynthetic tetracycline derivative, is widely used to inhibit microglial activation [139]. In AD animals, minocycline reduced AD symptoms by reducing neuroinflammation, CNS pathology, and preventing cell death [140, 141]. For instance, in APP/PS mice, minocycline increased the survival of new dentate granule cells and improved behavioral performance in a hippocampusdependent learning task [142]. In Tg2576 mice, minocycline attenuated deficits in learning and memory in $A \beta$ infused rats [140]. Clinical trials showed that minocycline is effective to treat chronic pain such as peripheral and autonomic neuropathies in type 2 diabetic patients [143], rheumatoid arthritis [144], and affective pain evaluated by McGill Pain Questionnaire in a cohort of patients with neuropathic pain, although the pain intensities did not change [145]. These data suggest that minocycline can reduce chronic pain and microglial activation in $\mathrm{AD}$ patient. However, the efficacy of minocycline in $\mathrm{AD}$ patients remains to be revealed, although one clinical trial is evaluating minocycline's efficacy in patients with mild cognitive impairment or AD (NCT01463384).

\section{Conclusions and future directions}

This review discusses the link between chronic pain and $\mathrm{AD}$ and a potential mechanism underlying this connection. Dysfunction of LC-NE system that may trigger proinflammatory activation of microglia in chronic pain 


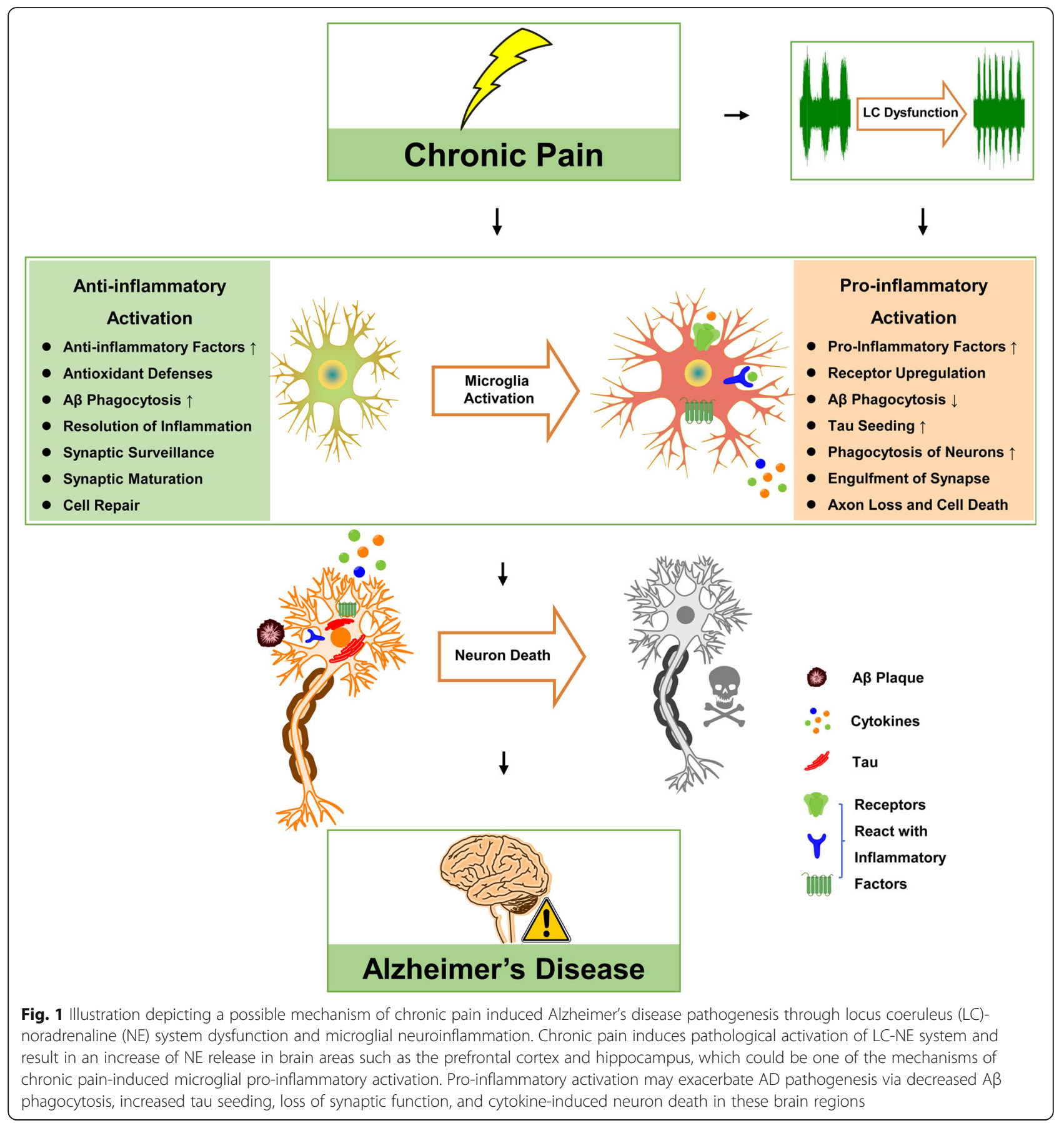

could be one of the bridges between chronic pain and AD aggravation (Fig. 1).

Though chronic pain-induced LC-NE dysfunction may aggravate $\mathrm{AD}$ pathogenesis through pro-inflammatory microglia, the pattern of LC-NE dysfunction in the comorbid $\mathrm{AD}$ and chronic pain state is not elucidated. Whether chronic pain induces neuronal loss in the LC has not been reported yet, but it is possible, especially with long-lasting pain (i.e., $>3$ months). Studies to examine whether chronic pain can induce or aggravate cognitive deficits as well as behavioral and psychiatric symptoms in aged and AD models would be helpful in beginning to confirm a causal relationship, and tracking AD-related biomarkers and pro-inflammatory factors released from activated microglia in brain regions related to $\mathrm{AD}$ pathogenesis, such as the PFC and hippocampus, would further help define pathological mechanisms. 


\section{Abbreviations}

AD: Alzheimer's disease; ASC: Apoptosis-associated speck-like protein containing a CARD; Aß: Amyloid-beta; CNS: Central nervous system; COX2: Cyclooxygenase 2; CREB: CAMP-response element binding protein: $\mathrm{D} \beta \mathrm{H}$ : Dopamine beta-hydroxylase; HCN: Hyperpolarization-activated cyclic nucleotide-gated; IL: Interleukin; iNOS: Inducible nitrous oxide synthase: LC: Locus coeruleus; L-DOPS: L-threo-3,4-dihydroxyphenylserine; LPS: Lipopolysaccharide; MAPK: Mitogen-activated protein kinase; MCP1: Monocyte chemotactic protein 1; mPFC: Medial prefrontal cortex; MRI: Magnetic resonance imaging; NE: Norepinephrine; NF-KB: Nuclear factor kappa-B; PET: Positron emission tomography; PET-MRI: Positron emission tomography-magnetic resonance imaging; PFC: Prefrontal cortex; PP: Amyloid precursor protein; TNF-a: Tumor necrosis factor alpha

\section{Acknowledgements}

Not applicable.

\section{Authors' contributions}

This work was primarily written by SC, DWF, TY, and HD. The figures were produced by SC. All authors read and approved the final manuscript.

\section{Funding}

This work is supported by the NIH grants R01AG062249-01 and RF1AG057884-02 (Dong H) and partly supported by the National Natural Science Foundation of China (81660201 to Cao S) and the Excellent Young Talents Project of Zunyi Medical University (18zy-004 to Cao S).

\section{Availability of data and materials}

Data sharing is not applicable to this article as no datasets were generated or analyzed during the current study.

\section{Ethics approval and consent to participate}

Not applicable.

\section{Consent for publication}

Not applicable.

\section{Competing interests}

The authors declare that they have no competing interests.

\section{Author details}

'Department of Pain Medicine, Affiliated Hospital of Zunyi Medical University, 149 Dalian Street, Zunyi 56300, Guizhou, China. ${ }^{2}$ Guizhou Key Lab of Anesthesia and Organ Protection, Affiliated Hospital of Zunyi Medical University, 149 Dalian Street, Zunyi 56300, Guizhou, China. ${ }^{3}$ Department of Psychiatry and Behavioral Sciences, Northwestern University Feinberg School of Medicine, 303 East Chicago Avenue, Chicago, IL 60611, USA.

\section{Received: 28 May 2019 Accepted: 27 September 2019}

Published online: 06 November 2019

\section{References}

1. Larsson C, Hansson EE, Sundquist K, Jakobsson U. Chronic pain in older adults: prevalence, incidence, and risk factors. Scand J Rheumatol. 2017:46:317-25.

2. Breivik H, Collett B, Ventafridda V, Cohen R, Gallacher D. Survey of chronic pain in Europe: prevalence, impact on daily life, and treatment. Eur J Pain. 2006;10:287-333.

3. van Dijk A, McGrath P, Pickett W, VanDenKerkhof EG. Pain prevalence in nine- to 13-year-old schoolchildren. Pain Res Manag. 2006;11:234-40.

4. Malfliet A, Coppieters I, Van Wilgen P, Kregel J, De Pauw R, Dolphens M, Ickmans K. Brain changes associated with cognitive and emotional factors in chronic pain: a systematic review. Eur J Pain. 2017;21:769-86.

5. Bushnell MC, Ceko M, Low LA. Cognitive and emotional control of pain and its disruption in chronic pain. Nat Rev Neurosci. 2013;14:502-11.

6. Navratilova E, Morimura K, Xie JY, Atcherley CW, Ossipov MH, Porreca F. Positive emotions and brain reward circuits in chronic pain. J Comp Neurol. 2016:524:1646-52.

7. Nishioka K, Hayashi T, Suzuki M, Li Y, Nakayama S, Matsushima T, Usui C, Shibata N, Motoi Y, Tanaka R, et al. Fibromyalgia syndrome and cognitive dysfunction in elderly: a case series. Int J Rheum Dis. 2016;19:21-9.
8. Kregel J, Schumacher C, Dolphens M, Malfliet A, Goubert D, Lenoir D, Cagnie B, Meeus M, Coppieters I. Convergent validity of the Dutch central sensitization inventory: associations with psychophysical pain measures, quality of life, disability, and pain cognitions in patients with chronic spinal pain. Pain Pract. 2018;18:777-87.

9. Tajerian M, Leu D, Zou Y, Sahbaie P, Li W, Khan H, Hsu V, Kingery W, Huang $\Pi$, Becerra L, Clark JD. Brain neuroplastic changes accompany anxiety and memory deficits in a model of complex regional pain syndrome. Anesthesiology. 2014;121:852-65.

10. Moriarty O, McGuire BE, Finn DP. The effect of pain on cognitive function: a review of clinical and preclinical research. Prog Neurobiol. 2011;93:385-404.

11. van Kooten J, Binnekade T, van der Wouden JC, Stek ML, Scherder EJ, Husebo BS, Smalbrugge M, Hertogh CM. A review of pain prevalence in Alzheimer's, vascular, frontotemporal and lewy body dementias. Dement Geriatr Cogn Disord. 2016;41:220-32.

12. Cravello L, Di Santo S, Varrassi G, Benincasa D, Marchettini P, de Tommaso M, Shofany J, Assogna F, Perotta D, Palmer K, et al. Chronic pain in the elderly with cognitive decline: a narrative review. Pain Ther. 2019;8(1):53-65. https://doi.org/10.1007/s40122-019-0111-7.

13. van Kooten J, Smalbrugge M, van der Wouden JC, Stek ML, Hertogh C. Prevalence of pain in nursing home residents: the role of dementia stage and dementia subtypes. J Am Med Dir Assoc. 2017;18:522-7.

14. Rajkumar AP, Ballard C, Fossey J, Orrell M, Moniz-Cook E, Woods RT, Murray J, Whitaker R, Stafford J, Knapp M, et al. Epidemiology of pain in people with dementia living in care homes: longitudinal course, prevalence, and treatment implications. J Am Med Dir Assoc. 2017;18:453.e451-6.

15. Whitlock EL, Diaz-Ramirez LG, Glymour MM, Boscardin WJ, Covinsky KE, Smith AK. Association between persistent pain and memory decline and dementia in a longitudinal cohort of elders. JAMA Intern Med. 2017;177:1146-53.

16. Scherder EJ, Eggermont L, Plooij B, Oudshoorn J, Vuijk PJ, Pickering G, Lautenbacher S, Achterberg W, Oosterman J. Relationship between chronic pain and cognition in cognitively intact older persons and in patients with Alzheimer's disease. The need to control for mood. Gerontology. 2008;54:50-8.

17. Hayashida K-i, Obata H. Strategies to treat chronic pain and strengthen impaired descending noradrenergic inhibitory system. Int J Mol Sci. 2019;20:822.

18. Salter MW, Stevens B. Microglia emerge as central players in brain disease. Nat Med. 2017:23:1018-27.

19. Gyoneva S, Traynelis SF. Norepinephrine modulates the motility of resting and activated microglia via different adrenergic receptors. J Biol Chem. 2013;288:15291-302.

20. Cha DS, Carmona NE, Mansur RB, Lee Y, Park HJ, Rodrigues NB, Subramaniapillai M, Rosenblat JD, Pan Z, Lee JH, et al. Pain and major depressive disorder: associations with cognitive impairment as measured by the THINC-integrated tool (THINC-it). Scand J Pain. 2017;15:62-7.

21. Leavitt F, Katz RS. Cross-sectional neurocognitive data do not support a transition from fibrofog to Alzheimer disease in fibromyalgia patients. J Clin Rheumatol. 2015;21:81-5.

22. Pickering G, Pereira B, Clere F, Sorel M, de Montgazon G, Navez M, Picard P, Roux D, Morel V, Salimani R, et al. Cognitive function in older patients with postherpetic neuralgia. Pain Pract. 2014;14:E1-7.

23. Baker KS, Gibson SJ, Georgiou-Karistianis N, Giummarra MJ. Relationship between self-reported cognitive difficulties, objective neuropsychological test performance and psychological distress in chronic pain. Eur J Pain. 2018;22:601-13.

24. Baker KS, Gibson S, Georgiou-Karistianis N, Roth RM, Giummarra MJ. Everyday executive functioning in chronic pain: specific deficits in working memory and emotion control, predicted by mood, medications, and pain interference. Clin J Pain. 2016:32:673-80.

25. Dick B, Eccleston C, Crombez G. Attentional functioning in fibromyalgia, rheumatoid arthritis, and musculoskeletal pain patients. Arthritis Rheum 2002:47:639-44

26. Brown SC, Glass JM, Park DC. The relationship of pain and depression to cognitive function in rheumatoid arthritis patients. Pain. 2002;96:279-84.

27. Grilli M. Chronic pain and adult hippocampal neurogenesis: translational implications from preclinical studies. J Pain Res. 2017:10:2281-6.

28. Katz MJ, Lipton RB, Hall CB, Zimmerman ME, Sanders AE, Verghese J, Dickson DW, Derby CA. Age-specific and sex-specific prevalence and incidence of mild cognitive impairment, dementia, and Alzheimer dementia in blacks and whites: a report from the Einstein Aging Study. Alzheimer Dis Assoc Disord. 2012;26:335-43. 
29. Ezzati A, Wang C, Katz MJ, Derby CA, Zammit AR, Zimmerman ME, Pavlovic JM, Sliwinski MJ, Lipton RB. The temporal relationship between pain intensity and pain interference and incident dementia. Curr Alzheimer Res. 2019;16(2):109115. https://doi.org/10.2174/1567205016666181212162424.

30. Corbett A, Husebo B, Malcangio M, Staniland A, Cohen-Mansfield J, Aarsland $D$, Ballard C. Assessment and treatment of pain in people with dementia. Nat Rev Neurol. 2012;8:264-74

31. Husebo BS, Achterberg W, Flo E. Identifying and managing pain in people with Alzheimer's disease and other types of dementia: a systematic review. CNS Drugs. 2016;30:481-97.

32. Santos $\mathrm{S}$, Castanho M. The use of visual analog scales to compare pain between patients with Alzheimer's disease and patients without any known neurodegenerative disease and their caregivers. Am J Alzheimers Dis Other Dement. 2014;29:320-5.

33. Ikram M, Innes K, Sambamoorthi U. Association of osteoarthritis and pain with Alzheimer's diseases and related dementias among older adults in the United States. Osteoarthr Cartil. 2019;27(10):1470-80. https://doi.org/10. 1016/j.joca.2019.05.021.

34. Baliki MN, Apkarian AV. Nociception, pain, negative moods, and behavior selection. Neuron. 2015;87:474-91.

35. Ng SK, Urquhart DM, Fitzgerald PB, Cicuttini FM, Hussain SM, Fitzgibbon BM. The relationship between structural and functional brain changes and altered emotion and cognition in chronic low back pain brain changes: a systematic review of MRI and fMRI studies. Clin J Pain. 2018;34:237-61.

36. Busatto GF, Diniz BS, Zanetti MV. Voxel-based morphometry in Alzheimer's disease. Expert Rev Neurother. 2008:8:1691-702.

37. Kang D, McAuley JH, Kassem MS, Gatt JM, Gustin SM. What does the grey matter decrease in the medial prefrontal cortex reflect in people with chronic pain? Eur J Pain. 2019;23:203-19.

38. Zhang Y, Yu T, Qin B, Li Y, Song G, Yu B. Microstructural abnormalities in gray matter of patients with postherpetic neuralgia: a diffusional kurtosis imaging study. Pain Physician. 2016;19:E601-11.

39. Apkarian AV, Sosa Y, Sonty S, Levy RM, Harden RN, Parrish TB, Gitelman DR. Chronic back pain is associated with decreased prefrontal and thalamic gray matter density. J Neurosci. 2004;24:10410-5.

40. Mutso AA, Radzicki D, Baliki MN, Huang L, Banisadr G, Centeno MV, Radulovic J, Martina M, Miller RJ, Apkarian AV. Abnormalities in hippocampal functioning with persistent pain. J Neurosci. 2012;32:5747-56.

41. Cao S, Qin B, Zhang Y, Yuan J, Fu B, Xie P, Song G, Li Y, Yu T. Herpes zoster chronification to postherpetic neuralgia induces brain activity and grey matter volume change. Am J Transl Res. 2018;10:184-99.

42. Phillips JS, Da Re F, Dratch L, Xie SX, Irwin DJ, McMillan CT, Vaishnavi SN, Ferrarese C, Lee EB, Shaw LM, et al. Neocortical origin and progression of gray matter atrophy in nonamnestic Alzheimer's disease. Neurobiol Aging. 2018;63:75-87.

43. Schmidt-Wilcke T, Poljansky S, Hierlmeier S, Hausner J, Ibach B. Memory performance correlates with gray matter density in the ento-/perirhinal cortex and posterior hippocampus in patients with mild cognitive impairment and healthy controls--a voxel based morphometry study. Neuroimage. 2009;47:1914-20.

44. Pais-Vieira M, Mendes-Pinto MM, Lima D, Galhardo V. Cognitive impairment of prefrontal-dependent decision-making in rats after the onset of chronic pain. Neuroscience. 2009;161:671-9.

45. Gong WY, Wang R, Liu Y, Jin H, Zhao ZW, Wang YL, Li HY, Zhang X, Ni JX. Chronic monoarthritis pain accelerates the processes of cognitive impairment and increases the NMDAR subunits NR2B in CA3 of hippocampus from 5-month-old transgenic APP/PS1 mice. Front Aging Neurosci. 2017;9:123.

46. Aston-Jones G, Cohen JD. An integrative theory of locus coeruleusnorepinephrine function: adaptive gain and optimal performance. Annu Rev Neurosci. 2005;28:403-50.

47. Llorca-Torralba M, Borges G, Neto F, Mico JA, Berrocoso E. Noradrenergic locus coeruleus pathways in pain modulation. Neuroscience. 2016;338:93-113.

48. Valentino RJ, Van Bockstaele E. Convergent regulation of locus coeruleus activity as an adaptive response to stress. Eur J Pharmacol. 2008;583:194-203.

49. Alba-Delgado C, Llorca-Torralba M, Horrillo I, Ortega JE, Mico JA, SanchezBlazquez P, Meana JJ, Berrocoso E. Chronic pain leads to concomitant noradrenergic impairment and mood disorders. Biol Psychiatry. 2013;73:54-62.

50. Suto T, Eisenach JC, Hayashida K. Peripheral nerve injury and gabapentin, but not their combination, impair attentional behavior via direct effects on noradrenergic signaling in the brain. Pain. 2014;155:1935-42.
51. Florin-Lechner SM, Druhan JP, Aston-Jones G, Valentino RJ. Enhanced norepinephrine release in prefrontal cortex with burst stimulation of the locus coeruleus. Brain Res. 1996;742:89-97.

52. Alba-Delgado C, Cebada-Aleu A, Mico JA, Berrocoso E. Comorbid anxietylike behavior and locus coeruleus impairment in diabetic peripheral neuropathy: a comparative study with the chronic constriction injury model. Prog Neuro-Psychopharmacol Biol Psychiatry. 2016;71:45-56.

53. Cordeiro Matos S, Zamfir M, Longo G, Ribeiro-da-Silva A, Seguela P. Noradrenergic fiber sprouting and altered transduction in neuropathic prefrontal cortex. Brain Struct Funct. 2018;223:1149-64.

54. Taylor BK, Westlund KN. The noradrenergic locus coeruleus as a chronic pain generator. J Neurosci Res. 2017;95:1336-46.

55. Butovsky O, Weiner HL. Microglial signatures and their role in health and disease. Nat Rev Neurosci. 2018;19:622-35.

56. Miner JJ, Diamond MS. Mechanisms of restriction of viral neuroinvasion at the blood-brain barrier. Curr Opin Immunol. 2016;38:18-23.

57. Fekete R, Cserep C, Lenart N, Toth K, Orsolits B, Martinecz B, Mehes E, Szabo $B$, Nemeth $V$, Gonci $B$, et al. Microglia control the spread of neurotropic virus infection via P2Y12 signalling and recruit monocytes through P2Y12independent mechanisms. Acta Neuropathol. 2018;136:461-82.

58. Jang H, Boltz D, Sturm-Ramirez K, Shepherd KR, Jiao Y, Webster R, Smeyne RJ. Highly pathogenic H5N1 influenza virus can enter the central nervous system and induce neuroinflammation and neurodegeneration. Proc Natl Acad Sci U S A. 2009;106:14063-8.

59. Colton CA. Heterogeneity of microglial activation in the innate immune response in the brain. J Neurolmmune Pharmacol. 2009;4:399-418.

60. Orihuela R, McPherson CA, Harry GJ. Microglial M1/M2 polarization and metabolic states. Br J Pharmacol. 2016;173:649-65.

61. Hains BC, Waxman SG. Activated microglia contribute to the maintenance of chronic pain after spinal cord injury. J Neurosci. 2006;26:4308-17.

62. Chen G, Zhang YQ, Qadri YJ, Serhan CN, Ji RR. Microglia in pain: detrimental and protective roles in pathogenesis and resolution of pain. Neuron. 2018; 100:1292-311.

63. Ma L, Nagai J, Ueda H. Microglial activation mediates de novo lysophosphatidic acid production in a model of neuropathic pain. J Neurochem. 2010;115:643-53.

64. Barcelon EE, Cho WH, Jun SB, Lee SJ. Brain microglial activation in chronic pain-associated affective disorder. Front Neurosci. 2019;13:213.

65. Liu Y, Zhou LJ, Wang J. TNF-alpha differentially regulates synaptic plasticity in the hippocampus and spinal cord by microglia-dependent mechanisms after peripheral nerve injury. J Neurosci. 2017;37:871-81.

66. Inoue K, Tsuda M. Microglia in neuropathic pain: cellular and molecular mechanisms and therapeutic potential. Nat Rev Neurosci. 2018;19:138-52.

67. Loggia ML, Chonde DB, Akeju O, Arabasz G, Catana C, Edwards RR, Hill E, Hsu S, Izquierdo-Garcia D, Ji RR, et al. Evidence for brain glial activation in chronic pain patients. Brain. 2015;138:604-15.

68. Albrecht DS, Forsberg A, Sandstrom A, Bergan C, Kadetoff D, Protsenko E, Lampa J, Lee YC, Hoglund CO, Catana C, et al. Brain glial activation in fibromyalgia - a multi-site positron emission tomography investigation. Brain Behav Immun. 2019;75:72-83.

69. Burke NN, Kerr DM, Moriarty O, Finn DP, Roche M. Minocycline modulates neuropathic pain behaviour and cortical M1-M2 microglial gene expression in a rat model of depression. Brain Behav Immun. 2014; $42: 147-56$

70. Xu N, Tang XH, Pan W, Xie ZM, Zhang GF, Ji MH, Yang JJ, Zhou MT, Zhou $Z Q$. Spared nerve injury increases the expression of microglia M1 markers in the prefrontal cortex of rats and provokes depression-like behaviors. Front Neurosci. 2017;11:209.

71. Dai J, Ding Z, Zhang J, Xu W, Guo Q, Zou W, Xiong Y, Weng Y, Yang Y, Chen $S$, et al. Minocycline relieves depressive-like behaviors in rats with bone cancer pain by inhibiting microglia activation in hippocampus. Anesth Analg. 2019. https://doi.org/10.1213/ANE.0000000000004063.

72. Miyamoto K, Kume K, Ohsawa M. Role of microglia in mechanical allodynia in the anterior cingulate cortex. J Pharmacol Sci. 2017;134:158-65.

73. Taylor AM, Mehrabani S, Liu S, Taylor AJ, Cahill CM. Topography of microglial activation in sensory- and affect-related brain regions in chronic pain. J Neurosci Res. 2017;95:1330-5.

74. Gui WS, Wei X, Mai CL, Murugan M, Wu LJ, Xin WJ, Zhou LJ, Liu XG. Interleukin-1beta overproduction is a common cause for neuropathic pain, memory deficit, and depression following peripheral nerve injury in rodents. Mol Pain. 2016;12. https://doi.org/10.1177/1744806916646784. 
75. Ji RR, Nackley A, Huh Y, Terrando N, Maixner W. Neuroinflammation and central sensitization in chronic and widespread pain. Anesthesiology. 2018;129:343-66.

76. Gannon M, Che P, Chen Y, Jiao K, Roberson ED, Wang Q. Noradrenergic dysfunction in Alzheimer's disease. Front Neurosci. 2015;9:220.

77. Simic G, Babic Leko M, Wray S, Harrington CR, Delalle I, Jovanov-Milosevic N, Bazadona D, Buee L, de Silva R, Di Giovanni G, et al. Monoaminergic neuropathology in Alzheimer's disease. Prog Neurobiol. 2017;151:101-38.

78. Matthews KL, Chen CP, Esiri MM, Keene J, Minger SL, Francis PT. Noradrenergic changes, aggressive behavior, and cognition in patients with dementia. Biol Psychiatry. 2002;51:407-16.

79. German DC, Manaye KF, White CL 3rd, Woodward DJ, McIntire DD, Smith WK, Kalaria RN, Mann DM. Disease-specific patterns of locus coeruleus cell loss. Ann Neurol. 1992;32:667-76.

80. Andrade-Moraes $\mathrm{CH}$, Oliveira-Pinto AV, Castro-Fonseca E, da Silva CG, Guimaraes DM, Szczupak D, Parente-Bruno DR, Carvalho LR, Polichiso L, Gomes BV, et al. Cell number changes in Alzheimer's disease relate to dementia, not to plaques and tangles. Brain. 2013;136:3738-52.

81. Szot P, White SS, Greenup JL, Leverenz JB, Peskind ER, Raskind MA. Changes in adrenoreceptors in the prefrontal cortex of subjects with dementia: evidence of compensatory changes. Neuroscience. 2007;146:471-80.

82. Szot P, Leverenz JB, Peskind ER, Kiyasu E, Rohde K, Miller MA, Raskind MA Tyrosine hydroxylase and norepinephrine transporter mRNA expression in the locus coeruleus in Alzheimer's disease. Brain Res Mol Brain Res. 2000;84:135-40.

83. Hoogendijk WJ, Feenstra MG, Botterblom MH, Gilhuis J, Sommer IE, Kamphorst W, Eikelenboom P, Swaab DF. Increased activity of surviving locus ceruleus neurons in Alzheimer's disease. Ann Neurol. 1999;45:82-91.

84. Gulyas B, Brockschnieder D, Nag S, Pavlova E, Kasa P, Beliczai Z, Legradi A, Gulya K, Thiele A, Dyrks T, Halldin C. The norepinephrine transporter (NET) radioligand (S,S)-[18F]FMeNER-D2 shows significant decreases in NET density in the human brain in Alzheimer's disease: a post-mortem autoradiographic study. Neurochem Int. 2010;56:789-98.

85. Elrod R, Peskind ER, DiGiacomo L, Brodkin Kl, Veith RC, Raskind MA. Effects of Alzheimer's disease severity on cerebrospinal fluid norepinephrine concentration. Am J Psychiatry. 1997;154:25-30.

86. Zarow C, Lyness SA, Mortimer JA, Chui HC. Neuronal loss is greater in the locus coeruleus than nucleus basalis and substantia nigra in Alzheimer and Parkinson diseases. Arch Neurol. 2003;60:337-41.

87. Heneka MT, Nadrigny F, Regen T, Martinez-Hernandez A, DumitrescuOzimek L, Terwel D, Jardanhazi-Kurutz D, Walter J, Kirchhoff F, Hanisch UK, Kummer MP. Locus ceruleus controls Alzheimer's disease pathology by modulating microglial functions through norepinephrine. Proc Natl Acad Sci U S A. 2010;107:6058-63.

88. Mravec B, Lejavova K, Vargovic P, Ondicova K, Horvathova L, Novak P, Manz G, Filipcik P, Novak M, Kvetnansky R. Tauopathy in transgenic (SHR72) rats impairs function of central noradrenergic system and promotes neuroinflammation. J Neuroinflammation. 2016;13:15

89. Itoi K, Ohara S, Kobayashi K. Selective ablation of dopamine betahydroxylase neurons in the brain by immunotoxin-mediated neuronal targeting: new insights into brain catecholaminergic circuitry and catecholamine-related diseases. Adv Pharmacol. 2013;68:155-66.

90. Barnard DF, Gabella KM, Kulp AC, Parker AD, Dugan PB, Johnson JD. Sex differences in the regulation of brain IL-1beta in response to chronic stress. Psychoneuroendocrinology. 2019;103:203-11.

91. Liu H, Leak RK, Hu X. Neurotransmitter receptors on microglia. Stroke Vasc Neurol. 2016;1:52-8.

92. Mori K, Ozaki E, Zhang B, Yang L, Yokoyama A, Takeda I, Maeda N, Sakanaka $M$, Tanaka J. Effects of norepinephrine on rat cultured microglial cells that express alpha1, alpha2, beta1 and beta2 adrenergic receptors. Neuropharmacology. 2002;43:1026-34.

93. Yang JH, Lee EO, Kim SE, Suh YH, Chong YH. Norepinephrine differentially modulates the innate inflammatory response provoked by amyloid-beta peptide via action at beta-adrenoceptors and activation of CAMP/PKA pathway in human THP-1 macrophages. Exp Neurol. 2012; 236:199-206

94. Schlachetzki JC, Fiebich BL, Haake E, de Oliveira AC, Candelario-Jalil E, Heneka MT, Hull M. Norepinephrine enhances the LPS-induced expression of COX-2 and secretion of PGE2 in primary rat microglia. J Neuroinflammation. 2010;7:2

95. Kato TA, Yamauchi Y, Horikawa H, Monji A, Mizoguchi Y, Seki Y, Hayakawa K, Utsumi H, Kanba S. Neurotransmitters, psychotropic drugs and microglia: clinical implications for psychiatry. Curr Med Chem. 2013;20:331-44.
96. Scanzano A, Cosentino M. Adrenergic regulation of innate immunity: a review. Front Pharmacol. 2015;6:171.

97. Feinstein DL, Heneka MT, Gavrilyuk V, Dello Russo C, Weinberg G, Galea E. Noradrenergic regulation of inflammatory gene expression in brain. Neurochem Int. 2002;41:357-65.

98. Dello Russo C, Boullerne Al, Gavrilyuk V, Feinstein DL. Inhibition of microglial inflammatory responses by norepinephrine: effects on nitric oxide and interleukin-1 beta production. J Neuroinflammation. 2004;1:9.

99. Markus T, Hansson SR, Cronberg T, Cilio C, Wieloch T, Ley D. betaAdrenoceptor activation depresses brain inflammation and is neuroprotective in lipopolysaccharide-induced sensitization to oxygenglucose deprivation in organotypic hippocampal slices. J Neuroinflammation. 2010;7:94.

100. Thery C, Dobbertin A, Mallat M. Downregulation of in vitro neurotoxicity of brain macrophages by prostaglandin E2 and a beta-adrenergic agonist. Glia. 1994;11:383-6.

101. Farber K, Pannasch U, Kettenmann H. Dopamine and noradrenaline control distinct functions in rodent microglial cells. Mol Cell Neurosci. 2005;29:128-38.

102. Hamelin L, Lagarde J, Dorothee G, Leroy C, Labit M, Comley RA, de Souza LC, Corne H, Dauphinot L, Bertoux M, et al. Early and protective microglial activation in Alzheimer's disease: a prospective study using 18F-DPA-714 PET imaging. Brain. 2016;139:1252-64.

103. Fan Z, Brooks DJ, Okello A, Edison P. An early and late peak in microglial activation in Alzheimer's disease trajectory. Brain. 2017;140:792-803.

104. Olmos-Alonso A, Schetters ST, Sri S, Askew K, Mancuso R, Vargas-Caballero M, Holscher C, Perry VH, Gomez-Nicola D. Pharmacological targeting of CSF1R inhibits microglial proliferation and prevents the progression of Alzheimer's-like pathology. Brain. 2016;139:891-907.

105. Kamphuis W, Orre M, Kooijman L, Dahmen M, Hol EM. Differential cell proliferation in the cortex of the APPswePS1dE9 Alzheimer's disease mouse model. Glia. 2012;60:615-29.

106. Martin E, Boucher C, Fontaine B, Delarasse C. Distinct inflammatory phenotypes of microglia and monocyte-derived macrophages in Alzheimer's disease models: effects of aging and amyloid pathology. Aging Cell. 2017;16:27-38.

107. Kamphuis W, Kooijman L, Schetters S, Orre M, Hol EM. Transcriptional profiling of CD11c-positive microglia accumulating around amyloid plaques in a mouse model for Alzheimer's disease. Biochim Biophys Acta. 1862;2016:1847-60.

108. Shen Z, Bao X, Wang R. Clinical PET imaging of microglial activation: implications for microglial therapeutics in Alzheimer's disease. Front Aging Neurosci. 2018;10:314

109. Mosher Kl, Wyss-Coray T. Microglial dysfunction in brain aging and Alzheimer's disease. Biochem Pharmacol. 2014;88:594-604.

110. Heneka MT, McManus RM, Latz E. Inflammasome signalling in brain function and neurodegenerative disease. Nat Rev Neurosci. 2018;19:610-21.

111. Hansen DV, Hanson JE, Sheng M. Microglia in Alzheimer's disease. J Cell Biol. 2018; 217:459-72.

112. Mattiace LA, Davies P, Yen SH, Dickson DW. Microglia in cerebellar plaques in Alzheimer's disease. Acta Neuropathol. 1990;80:493-8.

113. Meyer-Luehmann M, Spires-Jones TL, Prada C, Garcia-Alloza M, de Calignon A, Rozkalne A, Koenigsknecht-Talboo J, Holtzman DM, Bacskai BJ, Hyman BT. Rapid appearance and local toxicity of amyloid-beta plaques in a mouse model of Alzheimer's disease. Nature. 2008:451:720-4.

114. Gold M, El Khoury J. Beta-amyloid, microglia, and the inflammasome in Alzheimer's disease. Semin Immunopathol. 2015;37:607-11.

115. Hirbec HE, Noristani HN, Perrin FE. Microglia responses in acute and chronic neurological diseases: what microglia-specific transcriptomic studies taught (and did not teach) us. Front Aging Neurosci. 2017;9:227.

116. Kawabe K, Takano K, Moriyama M, Nakamura Y. Microglia endocytose amyloid beta through the binding of transglutaminase 2 and milk fat globule EGF factor 8 protein. Neurochem Res. 2018;43:41-9.

117. Bolmont T, Haiss F, Eicke D, Radde R, Mathis CA, Klunk WE, Kohsaka S, Jucker M, Calhoun ME. Dynamics of the microglial/amyloid interaction indicate a role in plaque maintenance. J Neurosci. 2008;28:4283-92.

118. Rivest S. Regulation of innate immune responses in the brain. Nat Rev Immunol. 2009;9:429-39.

119. Meda L, Cassatella MA, Szendrei Gl, Otvos L Jr, Baron P, Villalba M, Ferrari D, Rossi F. Activation of microglial cells by beta-amyloid protein and interferon-gamma. Nature. 1995;374:647-50.

120. Wyss-Coray T. Inflammation in Alzheimer disease: driving force, bystander or beneficial response? Nat Med. 2006;12:1005-15. 
121. Balducci C, Forloni G. Novel targets in Alzheimer's disease: a special focus on microglia. Pharmacol Res. 2018;130:402-13.

122. Cameron B, Landreth GE. Inflammation, microglia, and Alzheimer's disease. Neurobiol Dis. 2010;37:503-9.

123. Calsolaro V, Edison P. Neuroinflammation in Alzheimer's disease: current evidence and future directions. Alzheimers Dement. 2016;12:719-32.

124. Heneka MT, Carson MJ, El Khoury J, Landreth GE, Brosseron F, Feinstein DL, Jacobs AH, Wyss-Coray T, Vitorica J, Ransohoff RM, et al. Neuroinflammation in Alzheimer's disease. Lancet Neurol. 2015;14:388-405.

125. Neniskyte U, Neher JJ, Brown GC. Neuronal death induced by nanomolar amyloid beta is mediated by primary phagocytosis of neurons by microglia. J Biol Chem. 2011;286:39904-13.

126. Wegiel J, Wang KC, Imaki H, Rubenstein R, Wronska A, Osuchowski M, Lipinski WJ, Walker LC, LeVine H. The role of microglial cells and astrocytes in fibrillar plaque evolution in transgenic APP (SW) mice. Neurobiol Aging. 2001;22:49-61

127. Venegas $C$, Kumar $S$, Franklin BS, Dierkes T, Brinkschulte R, Tejera D, Vieira-Saecker A, Schwartz S, Santarelli F, Kummer MP, et al. Microglia-derived ASC specks crossseed amyloid-beta in Alzheimer's disease. Nature. 2017;552:355-61.

128. Andres-Benito P, Fernandez-Duenas V, Carmona M, Escobar LA, TorrejonEscribano B, Aso E, Ciruela F, Ferrer I. Locus coeruleus at asymptomatic early and middle Braak stages of neurofibrillary tangle pathology. Neuropathol Appl Neurobiol. 2017:43:373-92.

129. Hopp SC, Lin Y, Oakley D, Roe AD, DeVos SL, Hanlon D, Hyman BT. The role of microglia in processing and spreading of bioactive tau seeds in Alzheimer's disease. J Neuroinflammation. 2018;15:269.

130. Asai H, Ikezu S, Tsunoda S, Medalla M, Luebke J, Haydar T, Wolozin B. Depletion of microglia and inhibition of exosome synthesis halt tau propagation. Nat Neurosci. 2015;18:1584-93.

131. Maphis N, Xu G, Kokiko-Cochran ON, Jiang S, Cardona A, Ransohoff RM, Lamb BT, Bhaskar K. Reactive microglia drive tau pathology and contribute to the spreading of pathological tau in the brain. Brain. 2015;138:1738-55.

132. Bhaskar K, Konerth M, Kokiko-Cochran ON, Cardona A, Ransohoff RM, Lamb BT. Regulation of tau pathology by the microglial fractalkine receptor. Neuron. 2010;68:19-31.

133. Tejera D, Heneka MT. Microglia in Alzheimer's disease: the good, the bad and the ugly. Curr Alzheimer Res. 2016;13:370-80.

134. Jhang KA, Lee EO, Kim HS, Chong YH. Norepinephrine provides short-term neuroprotection against Abeta1-42 by reducing oxidative stress independent of Nrf2 activation. Neurobiol Aging. 2014;35:2465-73.

135. Hammerschmidt T, Kummer MP, Terwel D, Martinez A, Gorji A, Pape HC, Rommelfanger KS, Schroeder JP, Stoll M, Schultze J, et al. Selective loss of noradrenaline exacerbates early cognitive dysfunction and synaptic deficits in APP/PS1 mice. Biol Psychiatry. 2013;73:454-63.

136. Mohs RC, Shiovitz TM, Tariot PN, Porsteinsson AP, Baker KD, Feldman PD. Atomoxetine augmentation of cholinesterase inhibitor therapy in patients with Alzheimer disease: 6-month, randomized, double-blind, placebocontrolled, parallel-trial study. Am J Geriatr Psychiatry. 2009;17:752-9.

137. Finnell JE, Moffitt CM, Hesser LA, Harrington E, Melson MN, Wood CS, Wood SK. The contribution of the locus coeruleus-norepinephrine system in the emergence of defeat-induced inflammatory priming. Brain Behav Immun. 2019; 79:102-13. https://doi.org/10.1016/.bbi.2019.01.021.

138. Fitzgerald PJ. Is elevated norepinephrine an etiological factor in some cases of Alzheimer's disease? Curr Alzheimer Res. 2010;7:506-16.

139. Tikka T, Fiebich BL, Goldsteins G, Keinanen R, Koistinaho J. Minocycline, a tetracycline derivative, is neuroprotective against excitotoxicity by inhibiting activation and proliferation of microglia. J Neurosci. 2001;21:2580-8.

140. Choi Y, Kim HS, Shin KY, Kim EM, Kim M, Kim HS, Park CH, Jeong YH, Yoo J, Lee JP, et al. Minocycline attenuates neuronal cell death and improves cognitive impairment in Alzheimer's disease models. Neuropsychopharmacology. 2007;32:2393-404.

141. Daulatzai MA. Pharmacotherpy and Alzheimer's disease: the M-drugs (melatonin, minocycline, modafinil, and memantine) approach. Curr Pharm Des. 2016;22:2411-30.

142. Biscaro B, Lindvall O, Tesco G, Ekdahl CT, Nitsch RM. Inhibition of microglial activation protects hippocampal neurogenesis and improves cognitive deficits in a transgenic mouse model for Alzheimer's disease. Neurodegener Dis. 2012;9:187-98

143. Syngle A, Verma I, Krishan P, Garg N, Syngle V. Minocycline improves peripheral and autonomic neuropathy in type 2 diabetes: MIND study. Neurol Sci. 2014;35:1067-73.
144. Pillemer SR, Fowler SE, Tilley BC, Alarcon GS, Heyse SP, Trentham DE, Neuner R, Clegg DO, Leisen JC, Cooper SM, et al. Meaningful improvement criteria sets in a rheumatoid arthritis clinical trial. MIRA trial group. Minocycline in rheumatoid arthritis. Arthritis Rheum. 1997;40:419-25.

145. Sumitani M, Ueda H, Hozumi J, Inoue R, Kogure T, Yamada Y, Kogure T. Minocycline does not decrease intensity of neuropathic pain intensity, but does improve its affective dimension. J Pain Palliat Care Pharmacother. 2016:30:31-5.

\section{Publisher's Note}

Springer Nature remains neutral with regard to jurisdictional claims in published maps and institutional affiliations.
Ready to submit your research? Choose BMC and benefit from:

- fast, convenient online submission

- thorough peer review by experienced researchers in your field

- rapid publication on acceptance

- support for research data, including large and complex data types

- gold Open Access which fosters wider collaboration and increased citations

- maximum visibility for your research: over $100 \mathrm{M}$ website views per year

At BMC, research is always in progress.

Learn more biomedcentral.com/submissions 